\title{
Bıldırcın Rasyonlarına Polen İlavesinin Besi Performansı ve Karkas
}

\section{Parametreleri Üzerine Etkisi**}

\author{
Yasin SARIKAYA ${ }^{1}$, Tuncay TUFAN ${ }^{2 *}$, Memiş BOLACALI $^{3}$ \\ ${ }^{1}$ Ardahan Üniversitesi Nihat Delibalta Göle Meslek Yüksek Okulu, Laborant ve Veteriner Sağık Programı 75002, Ardahan, \\ Türkiye. \\ ${ }^{2}$ Siirt Üniversitesi, Veteriner Fakültesi, Hayvan Besleme ve Beslenme Hastalıkları Anabilim Dalı, 56100 Siirt, Türkiye. \\ ${ }^{3}$ Siirt Üniversitesi, Veteriner Fakültesi, Zootekni Anabilim Dalı, 56100 Siirt, Türkiye.
}

Özet: Bu çalışma, bıldırcın (Coturnix Coturnix Japonica) rasyonlarına farklı oranlarda arı poleni ilavesinin canlı ağırlık, canlı ağırlık artışı, yem tüketimi, yemden yararlanma oranı ve bazı karkas parametreleri üzerine etkilerini belirlemek amacıyla yapıldı. Araştırmada bir günlük yaşta toplam 300 adet bıldırcın civcivi kullanılmıştır. Araştırma grupları, her biri 100 civcivden oluşan 3 ana gruba ve bu ana grupların her biri 25 civcivden oluşan 4 alt gruba ayrılmıştır. Bıldırcınlar için hazırlanan rasyonlarda, kontrol grubunda herhangi bir yem katkı maddesi kullanılmazken, diğer grupların yemlerine \% 0.25 (P1) ve 0.50 (P2) arı poleni ilave edilmiştir. Araştırma 42 gün sürmüştür. Deneme genelinde (1-42. günler) canlı ağırlık, canlı ağırlık artışı, yem tüketimi ve yemden yararlanma oranları bakımından gruplar arasında istatistiksel farklılık belirlenmemiştir $(P>0.05)$. Karkas parametrelerinden sıcak ve soğuk karkas ağırlıkları, kalp, karaciğer, taşlık, bağırsak, göğüs, but, kanat, sırt+boyun ve diğer ağırlıkları ve bağırsak uzunluğu bakımından gruplar arasında istatistiksel farklııı belirlenmemiştir. Abdominal yağ ağırlığı ve oranı bakımından P2 grubu kontrol grubuna göre düşük olduğu tespit edilmiştir $(P<0.05)$. Sıcak ve soğuk karkas oranları P1 ve $\mathrm{P} 2$ gruplarında kontrol grubundan yüksek olduğu belirlenmiştir $(\mathrm{P}<0.001)$. Sonuç olarak, bıldırcın rasyonlarına $\% 0.25$ ve 0.50 düzeylerinde arı poleni ilavesinin; 42 günlük araştırma süresince besi performansı üzerinde kontrol grubuna benzer sonuçlar oluşturması, sıcak ve soğuk karkas oranlarını iyileştirmesi ve abdominal yağ oranında azalmaya neden olmasından dolayı yem katkı maddesi olarak kullanılmasının yararlı olacağı kanaatine varılmıştır.

Anahtar Kelimeler: Besi performansı, Bıldırcın, Karkas ağırlığı, Arı poleni.

\section{Effects of Dietary Addition of Pollen on Growth Performance and Carcass Traits of Japanese Quail}

Abstract: This study was conducted for the purpose of determining the effects of adding bee pollens at different rates to quail (Coturnix Coturnix Japonica) rations on live weight, live weight gain, feed consumption, feed conversion ratio, and some carcass parameters. A total of 300 daily quail chicks were used in the study. The study groups were divided into 3 main groups each of which consisting of 100 chicks; and these main groups were divided into 4 sub-groups each of which consisting of 25 chicks. There were no additives in the ration that was prepared for the control group quails; and bee pollen was added to the rations of the other groups as $0.25 \%(P 1)$ and $0.50 \%$ (P2). The study lasted 42 days. During the course of the study $\left(1^{\text {st }}-42^{\text {nd }}\right.$ days) no statistically significant differences were determined among the groups in terms of live weight, live weight gain, feed consumption, and feed conversion ratio $(P>0.05)$. No statistically significant differences were determined among the groups in terms of hot and cold carcass weights, and the weights of heart, liver, gizzards intestines, chest, thighs, back-neck and other organs, and in terms of the length of the intestines, which are among the carcass parameters. In terms of abdominal fat weight and rate, the P2 group was determined to have lower values when compared with the control group $(\mathrm{P}<0.05)$. It was determined that hot and cold carcass rates in $\mathrm{P} 1$ and $\mathrm{P} 2$ groups were higher than those of the control group $(P<0.001)$. As a conclusion, it was concluded that adding bee pollen to quail rations at rates of $0.25 \%$ and $0.50 \%$ gave similar results with the control group in terms of feeding performance along the 42 -day study period. It was also concluded that it would be useful to use bee pollen as an additive to the rations since it improved hot and cold carcass rates; and caused that abdominal fat rates were reduced.

Keywords: Fattening performance, Quail, Carcass, Bee pollen.

\section{Giriş}

Çiftlik hayvanlarında uzun yıllar besi performansını artırıcı katkı maddesi olarak antibiyotikler kullanılmıştır. Avrupa Birliği ve ülkemizde 2006 yılında antibiyotiklerin yasaklanması ile beraber araştırmacılar antibiyotiğin gösterdiği etkiyi gösterebilecek alternatif yem katkıları arayışına girmişlerdir (Bolacali ve Irak,
2017; Tuncer, 2007). Antibiyotiklere alternatif olarak genellikle probiyotikler, prebiyotikler, humektanlar, bakteriyosinler, bitkisel ekstraktlar, organik asitler üzerine araştırmalar yapılmıştır (Ergün ve ark., 2014; Griggs ve Jacob, 2005). Son zamanlarda arı ve arı ürünlerinin yem katkı maddesi olarak kullanılabilirliği üzerine araştırmalar da 
yapılmaktadır. Polen, propolis, bal, balmumu, arı zehri ve arı sütü gibi spesifik arı ürünleri kimyasal yapısı ve biyolojik özelliklerinden dolayı pek çok alanda kullanılabilmektedir. Özellikle polen ve propolisin hayvan beslemede antibiyotiklere alternatif yem katkı maddesi olarak kullanılabilirliği ile ilgili araştırmalar son zamanlarda bilim adamlarının dikkatini çekmektedir (Doğan ve Hayoğlu, 2012; Popova ve ark., 2005). Arı poleni, proteinler, amino asitler, karbonhidratlar, lipidler, fenolik bileşikler, enzimler, vitaminler, mineraller ve aktif maddeler bakımından oldukça zengin bir üründür (Campos ve ark., 2008; Komosinska-Vassev ve ark., 2015).

Zengin besin madde içeriğine sahip olan arı poleninin protein içeriği ortalama $\% 20-30$ arasında olup, içerdiği proteinin yaklaşık \%10'unu metiyonin, lizin, treonin, histidin, lösin, izolösin, fenilalanin ve triptofan gibi esansiyel amino asitler oluşturmaktadır. Arı polenindeki sindirilebilir karbonhidrat düzeyi ortalama $\% 30$ oranında olup, özellikle fruktoz ve glukoz, toplam karbonhidratların yaklaşık \%25'ini oluşturmaktadırlar (AlmeidaMuradian ve ark., 2005; Roulston, 2000). Linoleik, Y- $^{-}$ linoleik ve archaic asitler gibi esansiyel yağ asitleri bakımından zengin bir içeriğe sahip olan polen, yaklaşık \%5-7 düzeyinde ham yağ içeriğine sahip olup önemli miktarda fosfolipidler ve fitosterolleri içermektedir (Campos ve ark., 2008; Szczesna, 2006). Ayrıca arı poleni yaklaşık \%1-2 düzeyinde flavonoidler, lökotrienler, kateşinler ve fenolik asitler gibi aktif bileşikleri de içermektedir (Asafova ve ark., 2001). Zengin bir kimyasal kompozisyona sahip olan polenin antioksidan özellikte olduğu da bildirilmektedir (Eraslan ve ark., 2009). Apiterapik ürün olarak kullanımı eski tarihlere dayanan arı ürünleri ve polenin besi performansını iyileştirici, antifungal, antimikrobiyal, antiviral, antienflamatuar, immünostimülasyon, lokal analjezik ve yanık yaralarının iyileşmesinde granülasyon sürecini kolaylaştırıcı etkisi bulunmaktadır (Almaraz-Abarca ve ark., 2004; Kroyer ve Hegedus, 2001; Pascoal ve ark., 2014). Babaei ve ark. (2016) polen, propolis ve balın bıldırcınlarda büyüme performansını iyileştirdiği; Oliveira ve ark. (2013) broyler rasyonlarına polen ilavesinin immunoglobulin düzeyini artırdığını; Hosseini ve ark. (2016) tavuk rasyonuna polen ve propolis ilavesinin sıcaklık ve stresten koruduğunu; Hascik ve ark. (2015) broyler rasyonlarına propolis ilavesinin et kalitesini iyileştirdiğini belirtmişlerdir.

Önceki yıllarda arı ürünleri üzerine yapılan araştırmalar olmasına rağmen antibiyotiğe alternatif performans arttırıcı yem katkı maddesi olarak rasyona hangi oranda polen ilave edilebileceği konusunda sınırlı bilgi bulunmaktadır. Bu çalışmada bıldırcın rasyonlarına farklı oranlarda arı poleni ilavesinin besi performansı ve karkas parametreleri üzerine etkisinin belirlenmesi amacıyla yapılmıştır.

\section{Materyal ve Metot}

Çalışma, Siirt Üniversitesi Hayvan Deneyleri Yerel Etik Kurulunun hayvan deneyleri kullanım kılavuzuna göre yürütüldü (Protokol no: 2017-01). Araştırmada hayvan materyali olarak Siirt Üniversitesi Yaban Hayvanları Araştırma ve Uygulama Merkezi'nden temin edilen 300 adet bir günlük yaşta, karışık cinsiyette Japon bıldırcın (Coturnix Coturnix Japonica) civcivi kullanıldı. Civcivlerin çıkım ağırlıkları belirlendikten sonra ortalama ağırlıkları birbirine yakın olacak şekilde, her ana grupta 100 civcivin olduğu kontrol, \%0.25 arı poleni (P1) ve \%0.50 arı poleni (P2) şeklinde gruplandırıldı. Her ana grupta bulunan 100 civciv kendi içinde her birinde 25 civciv bulunan 4 alt gruba ayrıldı. Araştırmada yem katkı maddesi olarak kullanılan arı poleni, Kars il merkezinden arı ve arı ürünleri malzemeleri satan ticari bir üreticiden temin edildi. Bıldırcınlar 1-42. günler arasında besin madde içerikleri NRC (1994)'ye uygun olarak hazırlanan bir rasyon (kontrol grubu) ile beslendi (Tablo 1). Kontrol grubu rasyonuna herhangi bir yem katkı maddesi ilavesi yapılmazken, diğer iki gruba $\% 0.25$ ve $\% 0.50$ oranlarında polen öğütülerek ilave edildi. $96 \times 46 \times 25 \mathrm{~cm}$ ölçülerindeki kafeslerin her birine 25 adet bıldırcın yerleştirildi. Illk hafta içerisinde kümes ısısının $32-34{ }^{\circ} \mathrm{C}$ olması sağlandı. Kafes ISISI araştırmanın 4. gününden itibaren her gün kademeli olarak düşürülerek $21{ }^{\circ} \mathrm{C}$ de sabitlendi. Kümes ortamında gün ışığı ve yapay aydınlatma uygulanarak 24 saat aydınlatma programı uygulandı. Araştırma 42 gün sürdürüldü. Yem ve su ad libitum olarak sağlandı.

Çalışmada civcivler çıkımdan itibaren 6 hafta boyunca $0.01 \mathrm{~g}$ hassasiyette elektronik terazi kullanılarak haftalık canlı ağırlıkları (CA) ile canlı ağırlık artışları (CAA) tespit edildi. İki tartım arasındaki canlı ağırık farkının 7'ye bölünmesiyle grupların ortalama günlük canlı ağırlık artışları (GCAA) belirlendi. Araştırmada haftalık kontrol ile deneme gruplarına verilen yemlerden artan yemler çıkartılıp, bulunan yem tüketim miktarları gruplardaki bıldırcın sayısına ve gün sayısına (7 gün) bölünerek ortalama bireysel günlük yem tüketimleri (YT) belirlendi. Bütün gruplarda, haftalık olarak yapılan tartımlardan elde edilen ortalama günlük YT'inin, GCAA'na bölünmesi ile yemden yararlanma oranı (YYO) tespit edildi. Araştırma sonunda kesim ve karkas parametrelerinin belirlenmesi için her alt gruptan ortalama CA'a en yakın 5 olmak üzere her ana gruptan toplam 20 bıldırcın kesildi. Kesilen bıldırcınların abdominal yağ, kalp, karaciğer, taşlık, barsak ağırlıkları ve bağırsak uzunlukları tespit edildi. İç organlar çıkarıldıktan sonra karkas 
tartılarak sıcak karkas ağırlığı belirlendi. Sıcak karkas ağılıkları belirlendikten sonra bıldırcın karkasları +4 을 24 saat bekletildi. Bekletilen bıldırcın karkasları 24 saatin sonunda tekrar tartılarak soğuk karkas ağırlıkları belirlendi. Sıcak ve soğuk karkas ağırlıklarının kesim ağırlığına oranı ile karkas randımanları tespit edildi. Soğuk karkas ağırlıkları belirlendikten sonra Genchev ve Mihaylov (2008)'a göre karkas parçalaması yapıldı. Karkasta göğüs, but, kanat, sırt+boyun ve diğer ağırlıkları ve bunların soğuk karkasa oranları tespit edildi. Araştırmada gruplardan elde edilen besi performansı ve karkas verim özelliklerine ait ortalamalar arasında istatistiksel farklılığın olup olmadığının belirlenmesinde varyans analizine bakıldı.Farklılık olan değerler arasındaki farkın önem kontrolü için DuncanMultipleRange (SPPS 23.0) testinden yararlanıldı (SPPS, 2015).

Tablo 1: Araştırmada kullanılan bıldırcın yeminin bileşimi ve besin madde içeriği.

\begin{tabular}{|c|c|c|c|}
\hline İçerik & $\begin{array}{l}\text { Başlangıç- Büyütme Dönemi (1-42. } \\
\text { günler), \% }\end{array}$ & $\begin{array}{l}\text { Kuru Madde Bazında Besin Madde } \\
\text { İçeriği, \% }\end{array}$ & \\
\hline Misır & 45.30 & Kuru madde & 89.85 \\
\hline Buğday & 8.91 & Metabolik enerji kcal/kg ** & 2903 \\
\hline Bitkisel Yağ & 1.60 & Ham protein & 24.08 \\
\hline Soya Küspesi (\%48HP) & 30.00 & Ham yağ & 3.41 \\
\hline Balık Unu (\%64 HP) & 3.00 & Ham selüloz & 4.65 \\
\hline Ayçiçeği Küspesi (\%32 HP) & 9.00 & Ham kül & 5.64 \\
\hline Kireç Taşı & 1.16 & Kalsiyum** & 0.81 \\
\hline Vit. Min. prem. * & 0.25 & $\mathrm{P}^{* *}$ & 0.38 \\
\hline Tuz & 0.35 & $\mathrm{Na**}$ & 0.20 \\
\hline DCP & 0.20 & $\mathrm{Cl} * *$ & 0.28 \\
\hline Antioksidan & 0.08 & Met+Sis** & 0.85 \\
\hline \multirow[t]{3}{*}{ L-Treonin } & 0.15 & Lizin** & 1.30 \\
\hline & & Treonin** & 1.02 \\
\hline & & Triptofan** & 0.31 \\
\hline
\end{tabular}

*Vitamin-Mineral premiksi (DSM Nutritional Products): Diyet başına 13. 000 IU vitamin A, 3. 500 IU vitamin D3, $100 \mathrm{mg}$ E vitamini, 3 mg K3 vitamini, $3 \mathrm{mg} \mathrm{B1}$ vitamini, $8 \mathrm{mg}$ B2 vitamini, $6 \mathrm{mg}$ B6 vitamini, $30 \mathrm{mg}$ B12 vitamini, $30 \mathrm{mg}$ Niasin, $8 \mathrm{mg}$ kalsiyum-D-panthotenat, $2 \mathrm{mg}$ folik asit, $70 \mathrm{mg} \mathrm{C}$ vitamini, $70 \mathrm{mg}$ D-biotin, $200 \mathrm{mg}$ kolin klorür, $2 \mathrm{mg}$ canthaxanthin, $0.75 \mathrm{mg}$ apokarotenoik asit esther, $120 \mathrm{mg}$ Mn, 100 mg Zn, 90 mg Fe, 16 mg Cu, 1. 5 mg I, 0. 75 mg Co, 0. 30 mg Se. **: Hesaplama yoluyla bulunmuştur.

\section{Bulgular}

Bıldırcın rasyonlarına farklı oranlarda polen ilavesinin çeşitli dönemlerdeki bıldırcın canlı ağırlıkları üzerine etkileri Tablo 2'de verilmiştir. Araştırmada kontrol grubunun 1,2 ve 3 . haftalardaki ortalama CA'ı her iki polen ilave edilmiş deneme gruplarından yüksek olduğu tespit edilirken, çalışmanın son üç haftasında canlı ağırlık ortalamaları bakımından tüm gruplar arasında fark olmadığı belirlendi $(P>0.05)$. Besi performansı parametrelerinin verildiği Tablo 3'te de görüldüğü üzere başlangıç dönemi GCAA bakımından kontrol grubu P1 ve P2 gruplarından önemli derecede yüksek tespit edilirken $(P<0.05)$, en yüksek $Y T$ ise Kontrol grubunda belirlendi ( $P>0.05)$. Başlangıç döneminde YYO bakımından gruplar arasında istatistiksel farklılık belirlenmedi ( $P>0.05)$. Büyütme döneminde GCAA bakımından P1 grubu kontrol grubundan yüksek olduğu belirlenirken $(P<0.05)$, YT ve YYO oranı bakımından gruplar arasında istatistiksel farklılık tespit edilmedi ( $P>0.05)$. Deneme geneline bakıldığında GCAA, YT ve YYO bakımından gruplar arasında istatistiksel farklılık tespit edilmedi $(\mathrm{P}>0.05)$.

Tablo 2.Grupların haftalık canlı ağırlık ortalamaları, (g).

\begin{tabular}{|c|c|c|c|c|}
\hline \multirow[b]{2}{*}{ Hafta } & \multicolumn{4}{|c|}{ Deneme Grupları } \\
\hline & Kontrol & P1 & P2 & Önem \\
\hline Çıkım & $6.92 \pm 0.13$ & $7.02 \pm 0.11$ & $7.01 \pm 0.03$ & - \\
\hline 1 & $15.33 \pm 0.57^{\mathrm{a}}$ & $12.61 \pm 0.40^{b}$ & $13.23 \pm 0.22^{b}$ & $* *$ \\
\hline 2 & $52.47 \pm 0.84^{\mathrm{a}}$ & $48.29 \pm 0.12^{b}$ & $49.06 \pm 0.46^{b}$ & $* * *$ \\
\hline 3 & $94.45 \pm 1.65^{\mathrm{a}}$ & $88.64 \pm 0.90^{b}$ & $89.70 \pm 0.87^{b}$ & $*$ \\
\hline 4 & $133.82 \pm 3.09$ & $130.31 \pm 0.63$ & $130.64 \pm 1.68$ & - \\
\hline 5 & $162.30 \pm 3.30$ & $158.40 \pm 1.70$ & $158.81 \pm 1.13$ & - \\
\hline 6 & $182.61 \pm 3.79$ & $184.08 \pm 1.10$ & $178.64 \pm 0.45$ & - \\
\hline
\end{tabular}


Tablo 3. Grupların başlangıç, büyütme ve deneme geneli ortalama canlı ağırlık artışı (g/gün), yem tüketimi (g/gün) ve yemden yaralanma oranları (g/g).

\begin{tabular}{|c|c|c|c|c|}
\hline Grup/Parametreler & Kontrol & P1 & $\mathbf{P 2}$ & Önem \\
\hline \multicolumn{5}{|c|}{ Başlangıç dönemi (1-21. günler) } \\
\hline GCAA & $4.17 \pm 0.07^{\mathrm{a}}$ & $3.89 \pm 0.04^{b}$ & $3.94 \pm 0.04^{b}$ & $*$ \\
\hline YT & $12.12 \pm 0.20$ & $11.85 \pm 0.30$ & $11.81 \pm 0.13$ & - \\
\hline YYO & $2.91 \pm 0.01$ & $3.05 \pm 0.04$ & $3.00 \pm 0.05$ & - \\
\hline \multicolumn{5}{|c|}{ Büyütme dönemi (22-42. günler) } \\
\hline GCAA & $4.20 \pm 0.11^{b}$ & $4.55 \pm 0.03^{\mathrm{a}}$ & $4.24 \pm 0.13^{\mathrm{ab}}$ & $*$ \\
\hline YT & $22.05 \pm 0.42$ & $22.52 \pm 0.16$ & $21.86 \pm 0.13$ & - \\
\hline YYO & $5.26 \pm 0.10$ & $4.95 \pm 0.04$ & $5.17 \pm 0.10$ & - \\
\hline \multicolumn{5}{|c|}{ Deneme geneli (1-42. günler) } \\
\hline GCAA & $4.19 \pm 0.09$ & $4.22 \pm 0.03$ & $4.09 \pm 0.01$ & - \\
\hline YT & $17.10 \pm 0.30$ & $17.19 \pm 0.19$ & $16.83 \pm 0.10$ & - \\
\hline YYO & $4.08 \pm 0.02$ & $4.07 \pm 0.03$ & $4.11 \pm 0.03$ & - \\
\hline
\end{tabular}

Çalışmada Tablo 4 incelendiğinde abdominal yağ ağırlığı hariç, incelenen kesim ve karkas ağırlıkları bakımından gruplar arasında fark tespit edilmedi ( $P>0.05)$. Abdominal yağ ağırlığının en düşük P2 grubunda, en yüksek P1 grubunda olduğu belirlendi. Sıcak ve soğuk karkas oranları değerlendirildiğinde yeme ilave edilen polen ilavesinin oranı arttıkça karkas randımanın arttığı $(P<0.001)$, en yüksek randımanın $P 2$ grubunda olduğu saptandı. Abdominal yağ oranın P1 grubunda en yüksek olduğu, en düşük değerin ise $P 2$ grubunda olduğu belirlendi $(P<0.05)$. Polen ilave edilen gruplardaki but ve kanat oranları kontrol grubundan daha düşük olduğu tespit edildi $(P<0.05)$. Bağırsak uzunlukları incelendiğinde P1 grubu, P2 grubundan daha uzun olmasına karşın polen ilavesinin bağırsak uzunluğu üzerine etkisi önemsiz $(P>0.05)$ bulundu.

Tablo 4. Gruplarda ortalama kesim ve karkas ağırlığı (g) ve oranları.

\begin{tabular}{|c|c|c|c|c|}
\hline Parametreler & Kontrol & P1 & $\mathbf{P 2}$ & Önem \\
\hline \multicolumn{5}{|c|}{ Ağırlıklar (g) } \\
\hline Kesim & $184.59 \pm 5.06$ & $180.93 \pm 2.27$ & $175.07 \pm 1.72$ & - \\
\hline Sıcak Karkas & $128.53 \pm 2.40$ & $128.91 \pm 1.30$ & $128.05 \pm 1.33$ & - \\
\hline Soğuk Karkas & $127.30 \pm 2.43$ & $128.12 \pm 1.32$ & $126.70 \pm 1.41$ & - \\
\hline Abdominal Yağ & $1.17 \pm 0.13^{\mathrm{a}}$ & $1.36 \pm 0.17^{\mathrm{a}}$ & $0.81 \pm 0.08^{b}$ & $*$ \\
\hline Kalp & $1.59 \pm 0.05$ & $1.52 \pm 0.03$ & $1.59 \pm 0.04$ & - \\
\hline Karaciğer & $3.84 \pm 0.37$ & $3.82 \pm 0.25$ & $3.77 \pm 0.20$ & - \\
\hline Taşlık & $3.32 \pm 0.13$ & $3.56 \pm 0.16$ & $3.58 \pm 0.14$ & - \\
\hline Bağırsak & $4.19 \pm 0.42$ & $4.53 \pm 0.24$ & $4.05 \pm 0.23$ & - \\
\hline Bağırsak uzunluğu (cm) & $47.22 \pm 1.68$ & $47.42 \pm 1.03$ & $43.58 \pm 1.32$ & - \\
\hline Göğüs & $45.57 \pm 1.26$ & $46.03 \pm 0.40$ & $44.43 \pm 0.77$ & - \\
\hline But & $29.40 \pm 0.60$ & $28.51 \pm 0.38$ & $28.37 \pm 0.34$ & - \\
\hline Kanat & $10.13 \pm 0.26$ & $9.93 \pm 0.15$ & $9.57 \pm 0.13$ & - \\
\hline Sirt+Boyun & $24.69 \pm 0.68$ & $25.57 \pm 0.72$ & $26.32 \pm 0.58$ & - \\
\hline Diğer & $17.52 \pm 0.49$ & $18.08 \pm 0.47$ & $18.02 \pm 0.40$ & - \\
\hline \multicolumn{5}{|c|}{ Oranlar \% } \\
\hline Sicak Karkas & $69.96 \pm 0.70^{c}$ & $71.29 \pm 0.26^{b}$ & $73.14 \pm 0.17^{\mathrm{a}}$ & $* * *$ \\
\hline Soğuk Karkas & $69.27 \pm 0.67^{c}$ & $70.86 \pm 0.27^{b}$ & $72.35 \pm 0.22^{\mathrm{a}}$ & $* * *$ \\
\hline Abdominal Yağ & $0.63 \pm 0.07^{\mathrm{ab}}$ & $0.76 \pm 0.10^{\mathrm{a}}$ & $0.46 \pm 0.04^{b}$ & $*$ \\
\hline Kalp & $0.87 \pm 0.03$ & $0.84 \pm 0.02$ & $0.91 \pm 0.02$ & - \\
\hline Karaciğer & $2.07 \pm 0.19$ & $2.12 \pm 0.15$ & $2.15 \pm 0.11$ & - \\
\hline Taşlık & $1.81 \pm 0.06$ & $1.98 \pm 0.09$ & $2.05 \pm 0.08$ & - \\
\hline Bağırsak & $2.26 \pm 0.22$ & $2.51 \pm 0.14$ & $2.31 \pm 0.13$ & - \\
\hline Göğüs & $35.75 \pm 0.56$ & $35.98 \pm 0.42$ & $35.05 \pm 0.38$ & - \\
\hline But & $23.13 \pm 0.33^{\mathrm{a}}$ & $22.26 \pm 0.23^{b}$ & $22.40 \pm 0.19^{b}$ & $*$ \\
\hline Kanat & $7.96 \pm 0.14^{\mathrm{a}}$ & $7.75 \pm 0.09^{\mathrm{ab}}$ & $7.56 \pm 0.09^{b}$ & $*$ \\
\hline Sirt+Boyun & $19.39 \pm 0.38$ & $19.91 \pm 0.42$ & $20.77 \pm 0.39$ & - \\
\hline Diğer & $13.78 \pm 0.33$ & $14.10 \pm 0.29$ & $14.22 \pm 0.28$ & - \\
\hline
\end{tabular}

${ }^{a, b, c}$ : Aynı satırda farklı harflerle ifade edilen ortalamalar arasında fark önemlidir.

-: Önemli değil $(\mathrm{P}>0.05) ;{ }^{*}: \mathrm{P}<0.05 ;{ }^{* * *}: \mathrm{P}<0.001$.

\section{Tartışma ve Sonuç}

Yapılan bu araştırmada bıldırcın rasyonlarına arı poleni ilavesinin deneme geneli GCAA'ı etkilemediği tespit edilmiştir. Bu sonuca benzer 
şekilde Canogullari ve ark. (2009) ve Kleczek ve ark. (2014) kanatlı rasyonlarına polen ilavesinin GCAA'ı değiştirmediğini bildirmişlerdir. Hosseini ve ark. (2016) ise broyler rasyonlarına $20 \mathrm{~g} / \mathrm{kg}$ polen ilavesinin CA'ı önemli derecede artırdığını bildirmişlerdir. Attia ve ark. (2014) broyler rasyonlarına $300 \mathrm{mg} / \mathrm{kg}$ polen, $300 \mathrm{mg} / \mathrm{kg}$ propolis, $300 \mathrm{mg} / \mathrm{kg}$ polen $+300 \mathrm{mg} / \mathrm{kg}$ propolis ve $0.5 \mathrm{~g} / \mathrm{kg}$ Mannan oligosakkarit ilavesinin GCAA'ı kontrol grubuna göre iyileştirdiğini bildirmişlerdir $(P<0.05)$. Çalışmada, bıldırcın rasyonlarına \% 0.25 ve 0.50 oranlarında polen ilavesinin başlangıç döneminde GCAA'nı olumsuz etkilediği ancak büyütme dönemi ve deneme geneli dikkate alındığında polen katkısının GCAA üzerine herhangi bir olumsuz etkisinin olmadığı sonucuna benzer olarak Canogullari ve ark. (2009) bıldırcın rasyonlarına 5, 10,15 ve $20 \mathrm{~g} / \mathrm{kg}$ düzeylerinde polen ilavesinin GCAA etkilemediğini bildirmişlerdir. Babaei ve ark. (2016) bıldırcın rasyonlarına $1000 \mathrm{mg} / \mathrm{kg}$ propolis ekstraktı ve $1000 \mathrm{mg} / \mathrm{kg}$ polen ilavesinin GCAA üzerinde herhangi bir etkisinin olmadığını ve kontrol grubuna benzer sonuçlar elde ettiklerini belirtmişlerdir. Seven ve ark. (2013) farklı yerleşim sıklığında yetiştirilen bıldırcın rasyonlarına $1 \mathrm{~g} / \mathrm{kg}$ polen ilave edilmesinin GCAA rakamsal olarak iyileştirdiğini ancak istatistiksel fark oluşturmadığını bildirmişlerdir. Bu sonuçlardan farklı olarak, Farag ve Rayes (2016) bıldırcın rasyonlarına \% 0.6 polen ilavesinin GCAA iyileştirdiğini bildirmişlerdir. Yapılan bu araştırmada deneme geneli (1-42. günler) dikkate alındığında ortalama YT bakımından gruplar arasında istatiksel olarak farklılık görülmemiştir $(P>0.05)$. Bu araştırma sonucuna benzer olarak Seven ve ark. (2013) bıldırcın rasyonlarına $1 \mathrm{~g} / \mathrm{kg}$ polen ilavesinin $\mathrm{YT}^{\prime}$ ini etkilemediğini bildirmişlerdir. $\mathrm{Bu}$ sonuçlardan farklı olarak, broyler rasyonlarına propolis ve polen ilavesinin $\mathrm{YT}^{\prime}$ ini önemli derecede düşürdüğü bildirilmektedir (Attia ve ark., 2014; Zeweil ve ark., 2016). Her iki bildirimden farklı olarak sıcaklık stresine maruz bırakılmış broyler rasyonlarına $20 \mathrm{~g} / \mathrm{kg}$ polen, $3 \mathrm{~g} / \mathrm{kg}$ propolis ve 20 $\mathrm{g} / \mathrm{kg}$ polen $+3 \mathrm{~g} / \mathrm{kg}$ propolis ilavesinin $\mathrm{YT}^{\prime}$ ini artırdığı bildirilmiştir (Hosseini ve ark., 2016). Bu araştırmada bıldırcın rasyonlarına polen ilavesinin deneme genelinde YYO'nı etkilemediği belirlenmiştir $(P>0.05)$. Bu araştırma sonucuna benzer olarak bıldırcın (Canogullari ve ark., 2009) ve broyler (Hosseini ve ark., 2016) rasyonlarına arı poleni ilavesinin YYO'nı etkilemediğini bildiren araştırma sonuçları da bulunmaktadır. Bu sonuçlardan farklı olarak, broyler rasyonlarına propolis ya da polen ilavesinin YYO'nı iyileştirdiğini bildiren sonuçlar da bulunmaktadır (Attia ve ark., 2014; Babaei ve ark., 2016).

Araştırma gruplarının kesim ve karkas ağırlıkları ile oranlarının verildiği Tablo 4'te; sıcak karkas ve soğuk karkas oranları ile abdominal yağ ağırlığı ve oranı, but ve kanat oranları hariç incelenen diğer tüm karkas parametrelerini bakımından gruplar arasında fark belirlenmemiştir. Bu araştırma sonuçlarına benzer olarak bıldırcın (Canogullari ve ark., 2009) ve broyler rasyonlarına (Hašèík ve ark., 2012) farklı dozlarda arı poleni ilavesinin kesim ağırlı̆̆ı, soğuk karkas oranı, kalp, karaciğer ve taşlık oranları üzerine etkisinin olmadığını bildirmişlerdir ( $P>0.05)$. Bu çalışma sonuçlarına göre bıldırcın rasyonlarına polen ilavesinin sıcak ve soğuk karkas oranlarını arttırması yönünden Farag ve Rayes (2016) ile Attia ve ark. (2011)'nın sonuçlarına benzer, ancak Canogullari ve ark. (2009), Hašèík ve ark. (2012) ve Hascik ve ark. (2015)'nın sonuçlarından farklı olduğu belirlenmiştir. Hascik ve ark. (2015) broiler rasyonuna propolis ilavesinin karkas, göğüs ve karaciğer oranlarını etkilemediğini ancak but oranını arttırdığını tespit etmişlerdir. Hascik ve ark. (2016)'nın yapmış olduğu başka bir araştırmada, broyler rasyonlarına propolis ilavesinin kesim ve karkas ağırlığı, karkas, kalp, karaciğer ve taşlık oranını etkilememesine karşın abdominal yağ ağırlığını $(\mathrm{P}<0.05)$ azalttığını tespit etmişlerdir.

Sonuç olarak, bıldırcın rasyonlarına \% 0.25 ve 0.50 düzeylerinde arı poleni ilavesinin; 42 günlük araştırma süresince besi performansı üzerinde kontrol grubuna benzer sonuçlar oluşturması ve olumsuz bir etkisinin olmaması, sıcak ve soğuk karkas oranlarını iyileştirmesi ve abdominal yağ oranında azalmaya neden olmasından dolayı yem katkı maddesi olarak kullanılmasının yararlı olacağı kanaatine varılmıştır.

\section{Kaynaklar}

Almaraz-Abarca N, Campos MDG, Avila-Reyes JA, Naranjo-Jim'enez N, Herrera-Corral J, Gonz'alezValdez LS, 2004: Variability of antioxidant activity among honeybee-collected pollen of different botanical origin. Interciencia, 29, 574-578.

Almeida-Muradian LB, Pamplona LC, Coimbra S, Barth OM, 2005: Chemical composition and botanical evaluation of dried bee pollen pellets. Journal of Food Composition and Analysis, 18, 105-111.

Asafova N, Orlov B, Kozin R, 2001: Physiologically Active Bee Products. edited by: Y. A. Nikolaev. Russia,

Attia YA, Al-Hamid AA, Ibrahim MS, Al-Harthi MA, Bovera F, Elnaggar AS, 2014: Productive performance, biochemical and hematological traits of broiler chickens supplemented with propolis, bee pollen, and mannan oligosaccharides continuously or intermittently. Livestock Science, 164, 87-95.

Attia YA, Al-Hanoun A, Tag El-Din AE., Bovera F, Shewika $Y$, 2011: Effect of bee polen levels on productive, reproductive and blood traits of NZW rabbits. J Anim Physiol Anim Nutr, 95, 294-303.

Babaei S, Rahimi S, Torshizi MAK, Tahmasebi G, Miran SNK, 2016: Effects of propolis, royal jelly, honey and bee pollen on growth performance and immune system of Japanese quails. In Veterinary Research 
Forum, Faculty of Veterinary Medicine, Urmia University, Urmia, Iran. 7, 13-20.

Bolacali M, Irak K, 2017: Effect of dietary yeast autolysate on performance, slaughter, and carcass characteristics, as well as blood parameters, in quail of both genders. South African Journal of Animal Science, 47, 460-470.

Campos MG, Bogdanov S, De Almeida-Muradian LB, Szczesna T, Mancebo Y, Frigerio C, Ferreira F, 2008: Pollen composition and standardisation of analytical methods. Journal of Apicultural Research, 47, 154161.

Canogullari S, Baylan, M, Sahinler N, Sahin A, 2009: Effects of propolis and polen supplementations on growth performance and body components of Japanese quails (Coturnix coturnix japonica). Arch. Geflugelk, 73, 173-178.

Doğan N, Hayoğlu I, 2012: Propolis ve kullanım alanları. Harran Tarım ve Gıda Bilimleri Dergisi, 16, 39-48.

Eraslan G, Kanbur M, Silici S, Liman BC, Altınordulu Ş, Sarıca ZS, 2009: Evaluation of protective effect of bee polen against propoxur toxicity in rat. Ecotoxicology and Environmental Safety, 72, 931937.

Ergün A, Çolpan I, Yıldız G, Küçükersan S, Tuncer Ş D, Yalçın S, Küçükersan MK, Şehu A, 2014: Hayvan besleme ve beslenme hastalıkları. Pozitif Matbaacılık, Ankara, s:47.

Farag Soha A, El-Rayes TK, 2016: Effect of Bee-pollen Supplementation on Performance, Carcass Traits and Blood Parameters of Broiler Chickens. Asian Journal of Animaland Veterinary Advances, 11, 168177.

Genchev A, Mihaylov R, 2008: Slaughter analysis protocol in experiments using Japanese quails (Coturnix Japonica). Trakia J. Sci. 6, 66-71.

Griggs JP, Jacob JP, 2005: Alternatives to antibiotics for organic poultry production. J, Appl, Poult, Res, 14 750-756.

Hascik $\mathrm{P}$, Trembecká $\mathrm{L}$, Bobko $\mathrm{M}$, Kačániová $\mathrm{M}$, Bučko $\mathrm{O}$, Tkáčová J, Kunová S, 2015: Effect of different feed supplements on selected quality indicators of chicken meat. Potravinarstvo Slovak Journal of Food Sciences, 9, 427-434.

Hascik P, Trembecká L, Bobko M, Kačániová M, Čuboň J, Kunová S, Bučko O, 2016: Effect of diet supplemented with propolis extract and probiotic additives on performance, carcass characteristic sand meat composition of broiler chickens. Potravinarstvo, 10, 223-231.

Hašèík P, Elimam I, Garlík J, Kacániová M, Cuboò J, Bobko M, Abdulla H, 2012: Impact of bee pollen as feed supplements on the body weight of broiler Ross 308. African Journal of Biotechnology, 11, 1559615599.

Hosseini SM., Azghandi MV, Ahani S, Nourmohammadi R, 2016. Effect of bee pollen and propolis (bee glue) on growth performance and biomarkers of heat stress in broiler chickens reared under high ambient temperature. J Anim Feed Sci, 25, 45-51.

Kleczek K, Wilkiewicz-Wawro E, Wawro K, Makowski W, Murawsk D, Wawro M, 2014: The effect of dietary propolis supplementation on the growth performance of broiler chickens. Pol J Natur Sc, 29, 105-117.

Komosinska-Vassev, K, Olczyk P, Kaźmierczak J, Mencner L, Olczyk K, 2015: Bee pollen: chemical composition and therapeutic application. Evidence-Based Complementary and Alternative Medicine (Erişim Tarihi:21.11.2017) (http://dx.doi.org/10.1155/2015/297425).

Kroyer G, Hegedus N, 2001: Evaluation of bioactive properties of pollen extracts as functional dietary food supplement. Innovative Food Science and Emerging Technologies, 2, 171-174.

NRC. (1994). Nutrient Requirements of Poultry 9th rev. ed. National Academy Press, Washington, DC.

Oliveira MC, Da Silva DM, Loch FC, Martins PC, Dias DMB, Simon GA, 2013: Effect of bee pollen on the immunity and tibia characteristics in broilers. Revista Brasileira de Ciência Avícola, 15, 323-327.

Pascoal A, Rodrigues S, Teixeira A, Feás X, Estevinho LM, 2014: Biological activities of commercial bee pollens: Antimicrobial, antimutagenic, antioxidant and anti-inflammatory. Food and Chemical Toxicology, 63, 233-239.

Popova M, Silici S, Kaftanoglu O, Bankova V, 2005: Antibacterial activity of Turkish propolis and its qualitative and quantitative chemical composition, Phytomedicine, 12, 221-228.

Roulston TH, Cane JH, 2000. Pollen nutritional content and digestibility for animals. Plant Systematics and Evolution, 222, 187-209.

Seven I, Seven PT, Aslan AS, Yıldız N, 2013. Farklı yerleşim sıklığında yetiştirilen Japon bıldırcınlarının (Coturnix coturnix japonica) performans parametreleri üzerine rasyona katılan multi enzimin etkileri. Fırat Üniversitesi Sağlık Bilimleri Veteriner Dergisi, 27, 155-158.

SPSS 2015: SPSS Base 23.0 for Windows User's Guide, Chicago, Illinois

Szczesna T, 2006: Long chain fatty acids composition of honeybeecollected pollen. Journal of Apicultural Science, 50, 65-79.

Tuncer Hi, 2007: Karma yemlerde kullanımı yasaklanan hormon, antibiyotik, antikoksidiyal ve ilaçlar. Lalahan Hayvancılık Araştırma Enstitüsü Dergisi, 47, 29-37.

Zeweil HS, Abd El-Rahman MHA, Dosoky WM, Abu Hafsa SH, Abdulhamid ABA, 2016: Effects of ginger and bee propolis on the performance, carcass characteristics and blood constituents of growing japanese quall. Egyptian Poultry Science Journal, 36, 143-159.

**Bu çalışma birinci isim yazarın Yüksek Lisans tezinden özetlenmiştir

*Yazışma Adresi: Tuncay TUFAN

Siirt Üniversitesi, Veteriner Fakültesi, Hayvan Besleme ve Beslenme Hastalıkları Anabilim Dalı, 56100 Siirt, Türkiye e-mail: tuncay-tufan@hotmail.com. 